\title{
La Ley General de Control del Tabaco y la opinión pública
}

\author{
Francisco Abundis ${ }^{(1)}$
}

$\mathrm{L}$ a mayoría de los mexicanos respalda la nueva ley - que prohíbe fumar en todos los lugares públicos cerrados y en los sitios de trabajo. En el Distrito Federal (DF), primera entidad donde se legisló sobre la materia, el apoyo a la legislación es ligeramente menor que en el resto del país.

De acuerdo con la Encuesta Nacional en Vivienda realizada por el Consejo Mexicano Contra el Tabaquismo y Parametría, en febrero de 2008 -antes de la aprobación de la Ley General de Control del Tabaco en todo el país-, $81 \%$ de la población manifestaba ya su apoyo a la norma, mientras que en el DF, 75\% de los ciudadanos decía que estaba de acuerdo con ella (figura 1).

Es interesante que antes de aprobarse la Ley de Protección a los No Fumadores en el DF, 80\% de los capitalinos manifestó su beneplácito con la misma, pero una vez ratificada la ley el apoyo disminuyó 5 puntos porcentuales.

El menor respaldo a la ley en la capital del país se explica por el mayor rechazo de los fumadores al nuevo reglamento. En octubre de 2007, 71\% de los fumadores en el DF dijo estar de acuerdo con la propuesta y cuatro meses después sólo $47 \%$ la apoyaba (figura 2).

Es probable que la experiencia del DF en este tema se repita de alguna forma en el resto del país. Es decir, que en una primera etapa se genere un fuerte apoyo -incluido el de fumadores- $y$ una vez que entre en vigor la ley el apoyo se reduzca debido al descontento de los fumadores.

Los lugares donde principalmente quiere la gente que se prohíba fumar son escuelas, instituciones de salud, transporte público, centros comerciales y lugares cerrados de trabajo. Los sitios en los que las personas exhiben cierta reticencia para que se prohíba fumar son antros y bares, playas, salones de juego, casas, hoteles, restaurantes o cafés, y autos.

Al parecer, la mayor o menor disposición para aceptar dejar de fumar en estos lugares depende del grado de exposición al humo del tabaco que suelen registrar normalmente. Así, en áreas que tradicionalmente no han estado tan expuestas al humo como escuelas y centros de salud, la sociedad reprueba mayoritariamente que se permita fumar, mientras que en lugares donde habitualmente existe un número más alto de fumadores, los mexicanos se muestran más tolerantes a la presencia del humo de cigarrillos (figura 3).

Un aspecto importante que las autoridades tendrán que considerar para el éxito de la Ley General de Control del Tabaco está relacionado con la correcta aplicación de las sanciones a quienes no la obedezcan.

En México, es sabido que desobedecer las leyes es una práctica muy común, a pesar de los beneficios que pueda generar. Lo anterior se refleja de alguna manera en la percepción que tienen los mexicanos sobre el acatamiento que hará la gente de la nueva legislación.

El 17\% de los entrevistados cree que las personas nunca obedecerán la ley antitabaco; una tercera parte piensa que la respetarán muy contadas veces; otro tercio opina que si bien se podría cumplir la norma en la mayoría de las ocasiones, siempre existirá la tentación a desobedecerla en ciertos momentos. Sólo 12\% confía en que se obedecerá plenamente, es decir, 8 de cada 10 personas dudan del pleno cumplimiento de la ley (figura 4). 


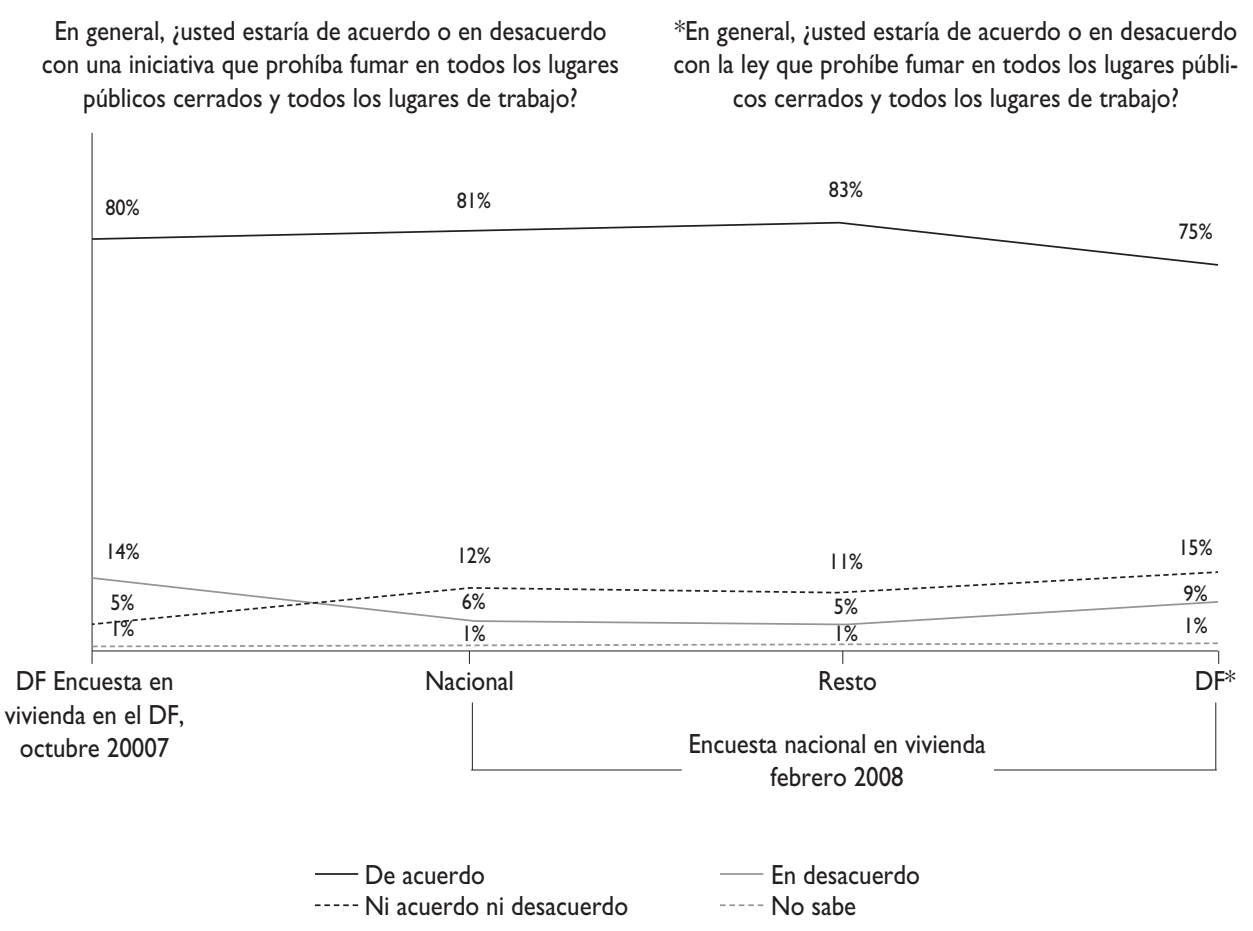

\footnotetext{
* La pregunta cambió para el DF por la Ley de Protección a los No Fumadores que recientemente aprobó la Asamblea Legislativa del Distrito Federal

Fuente: Parametría y Consejo Mexicano Contra el Tabaquismo
}

\section{Figura I. Opinión sobre la ley antitabaco. México, 2008}

En general, ¿usted estaría de acuerdo o en desacuerdo con una iniciativa que prohíba fumar en todos los lugares públicos cerrados y todos los lugares de trabajo?
*En general, ¿usted estaría de acuerdo o en desacuerdo con la ley que prohíbe fumar en todos los lugares públicos cerrados y todos los lugares de trabajo?

\begin{tabular}{|c|c|c|c|c|c|c|}
\hline & $\begin{array}{c}\text { De acuerdo } \\
\%\end{array}$ & $\begin{array}{c}\text { En desacuerdo } \\
\%\end{array}$ & $\begin{array}{c}\text { Ni acuerdo ni desacuerdo } \\
\%\end{array}$ & $\begin{array}{l}\text { No sabe } \\
\%\end{array}$ & $\begin{array}{c}\text { No contesta } \\
\%\end{array}$ & $\begin{array}{c}\text { Total } \\
\%\end{array}$ \\
\hline \multicolumn{7}{|l|}{ Octubre 2007} \\
\hline Población general & 80 & 14 & 5 & I & 0 & 100 \\
\hline Fumadores & 71 & 21 & 6 & i & । & 100 \\
\hline No fumadores & 84 & 10 & 5 & i & 0 & 100 \\
\hline \multicolumn{7}{|l|}{ Febrero $2008 *$} \\
\hline Población general & 75 & 9 & 15 & I & 0 & 100 \\
\hline Fumadores & 47 & 22 & 30 & I & 0 & 100 \\
\hline No fumadores & 86 & 4 & 9 & 0 & I & 100 \\
\hline
\end{tabular}

* La pregunta cambió para el estudio del 2008 por la Ley de Protección a los No Fumadores que recientemente aprobó la Asamblea Legislativa del Distrito Federal

Fuente: Parametría y Consejo Mexicano Contra el Tabaquismo

Figura 2. Opinión sobre la ley antitabaco. México, 2008 
¿Usted está de acuerdo o en desacuerdo con que se prohíba fumar en los siguientes lugares (...)?

\begin{tabular}{|c|c|c|c|c|c|c|c|}
\hline & \multicolumn{2}{|c|}{ Nacional } & \multicolumn{2}{|c|}{ Resto del país } & \multicolumn{2}{|c|}{ Distrito Federal } & \\
\hline Instituciones educativas & $3 \%$ & $\square 91 \%$ & $2 \%$ & $90 \%$ & $6 \%$ & & $91 \%$ \\
\hline Instituciones de salud & $3 \%$ & $91 \%$ & $2 \%$ & $90 \%$ & $6 \%$ & & $91 \%$ \\
\hline Transporte público & $5 \%$ & $85 \%$ & $3 \%$ & $84 \%$ & $8 \%$ & & $85 \%$ \\
\hline Centros comerciales & $7 \%$ & $83 \%$ & $6 \%$ & $82 \%$ & $10 \%$ & & $83 \%$ \\
\hline Lugares de trabajo & $9 \%$ & $83 \%$ & $7 \%$ & $82 \%$ & $14 \%$ & & $80 \%$ \\
\hline Coche & $23 \%$ & $65 \%$ & $16 \%$ & $70 \%$ & $34 \%$ & $57 \%$ & \\
\hline Restaurantes/Cafés & $26 \%$ & $61 \%$ & $19 \%$ & $67 \%$ & $36 \%$ & $55 \%$ & \\
\hline Hoteles & $21 \%$ & $60 \%$ & $13 \%$ & $68 \%$ & $36 \%$ & $47 \%$ & \\
\hline Casa propia & $30 \%$ & $57 \%$ & $24 \%$ & $62 \%$ & $38 \%$ & $50 \%$ & \\
\hline Salones de juego & $27 \%$ & $53 \%$ & $21 \%$ & $57 \%$ & $37 \%$ & $49 \%$ & \\
\hline Playas & $33 \%$ & $47 \%$ & $25 \%$ & $54 \%$ & $45 \%$ & $36 \%$ & \\
\hline Antros/bares & $41 \%$ & $41 \%$ & $32 \%$ & $48 \%$ & $54 \%$ & $34 \%$ & \\
\hline
\end{tabular}

Nota: Suma 100\% agregado "Ni acuerdo ni en desacuerdo", "No sabe" y "'No contesta"

Fuente: Parametría y Consejo Mexicano Contra el Tabaquismo

Figura 3. Espacios libres de humo. México, 2008

Si se aprobara una ley de espacios libres de humo, ¿usted cree que la gente la obedecería plenamente, la obedecería con algunas excepciones, la obedecería más bién poco o nunca?

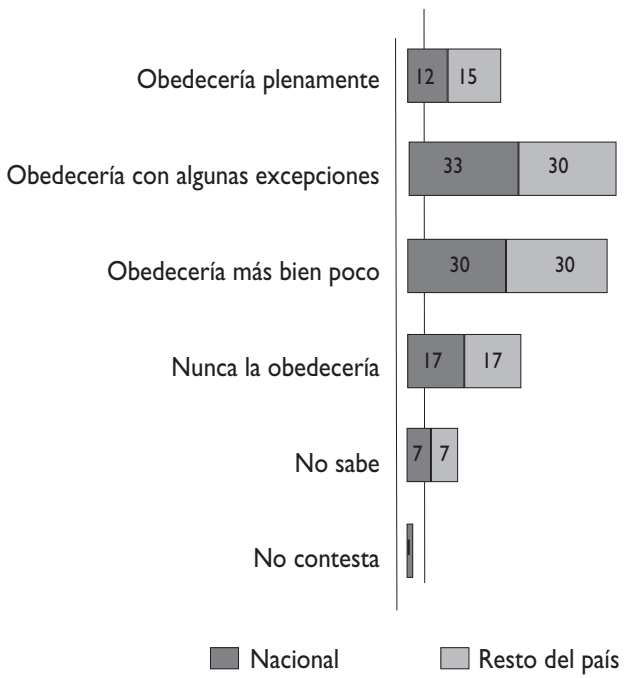

* iUsted cree que a partir de estos seis meses, la ley se obedecerá plenamente, se obedecerá con algunas excepciones, se obedecerá más bien poco o nunca?

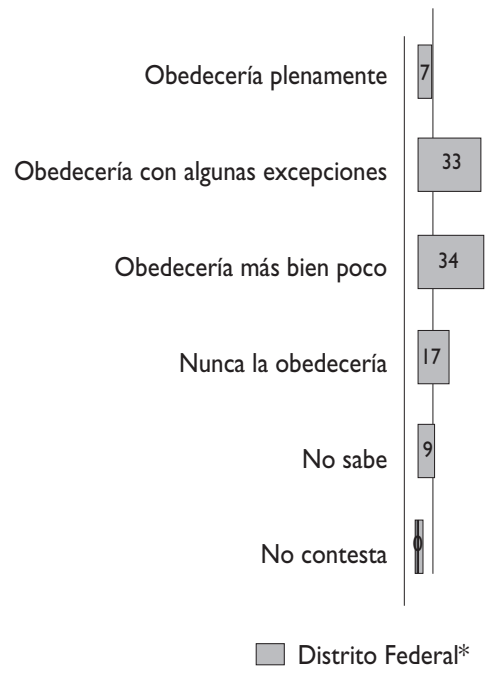

* La pregunta cambió para el DF por la Ley de Protección a los No Fumadores que recientemente aprobó la Asamblea Legislativa del Distrito Federal

Fuente: Parametría y Consejo Mexicano Contra el Tabaquismo

Figura 4. Respeto de la ley antitabaco. México, 2008 
Como es probable que siempre existan personas que traten de hacer caso omiso de la ley, las autoridades estarán en posibilidad de recaudar recursos económicos a través de las multas que impongan.

En este sentido, la sociedad considera que el dinero de las multas aplicadas a los establecimientos que violen la ley se debería destinar, en primer lugar, a las instituciones de salud (46\%); en segunda instancia, a los centros de rehabilitación que ayudan a la gente a dejar de fumar (26\%); y como tercera opción, a investigación de medicamentos para dejar de fumar (14\%) (figura 5).

Adicionalmente, la población considera que el gobierno debería tener una participación más activa en este asunto. Específicamente, los mexicanos apoyan la idea de que el Estado gaste parte de los impuestos en instrumentar programas para ayudar a los fumadores a dejar de fumar (figura 6).

Sin duda habrá que esperar para ver cuáles son las implicaciones de la reciente ley antitabaco. Aunque por el momento las opiniones se encuentran divididas.

El dinero que se recaude por las multas aplicadas a los establecimientos que violaran la ley de espacios libres de humo, ¿a dónde cree usted que se debería destinar?

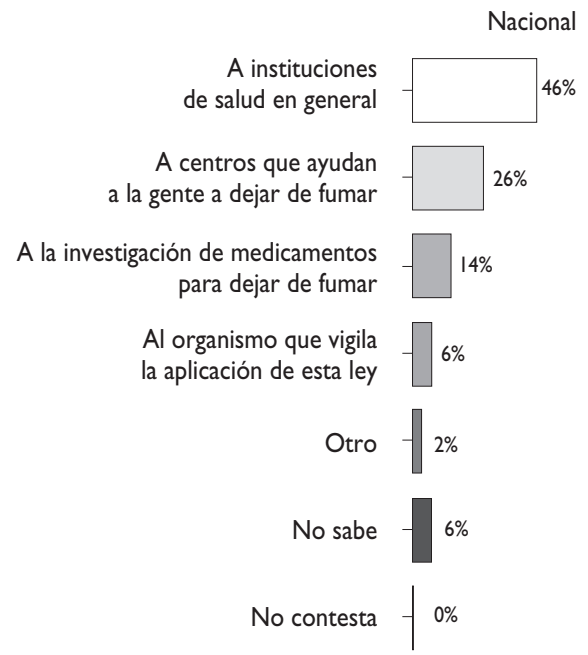

En el ámbito nacional, poco menos de la mitad de los mexicanos (47\%) indica que prohibir fumar en lugares públicos cerrados ayudará a reducir el número de fumadores. Pero en el DF -lugar donde ya estaba aprobada la ley local cuando se realizó la encuesta- la proporción es menor (40\%) (figura 7).

Los datos de la encuesta dejan entrever que el éxito de la Ley General de Control del Tabaco en México estará en función de dos factores principalmente: a) la correcta aplicación de la ley; b) la creación de una nueva cultura y cambio de hábitos entre fumadores y no fumadores.

Finalmente, habría que mencionar que si bien el número de fumadores se ha reducido entre los mayores de 18 años de 2003 a la fecha, y que la conciencia sobre los derechos de las personas a tener espacios libres de tabaco ha aumentado, un buen número de mexicanos continúa fumando, lo cual muestra la necesidad de que se siga trabajando en el problema del tabaquismo desde el gobierno y la sociedad civil.

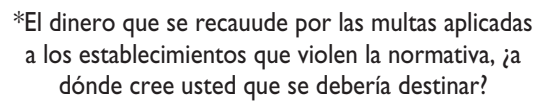

los establecimientos que violen la normativa, ia dónde cree usted que se debería destinar?

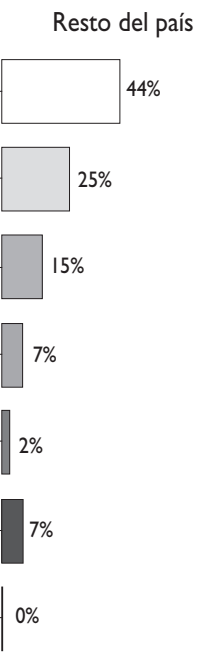

* La pregunta cambió para el DF por la Ley de Protección a No Fumadores que recientemente aprobó la Asamblea Legislativa del Distrito Federal

Fuente: Parametría y Consejo Mexicano Contra el Tabaquismo

Figura 5. Sanciones y destino de los recursos de la ley antitabaco. México, 2008 
¿Usted cree que el gobierno debe gastar o no parte de los impuestos en instrumentar programas para ayudar a los fumadores a dejar de fumar?

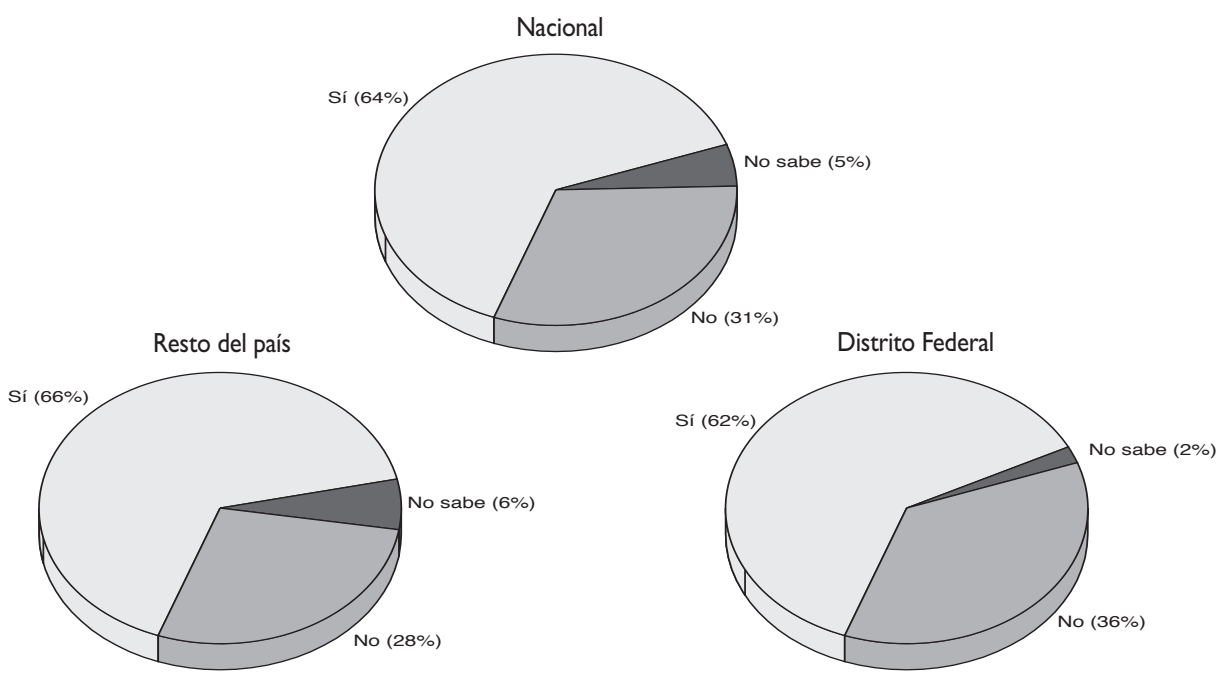

Fuente: Parametría y Consejo Mexicano Contra el Tabaquismo

Figura 6. Responsabilidad del gobierno en el tabaquismo. México, 2008

Si se prohibiera fumar en todos los lugares públicos cerrados $y$ todos los lugares de trabajo, iusted cree que el número de fumadores disminuiría o no?
*Al prohibirse fumar en todos los lugares públicos cerrados y todos los lugares de trabajo, iusted cree que el número de fumadores disminuiría o no?

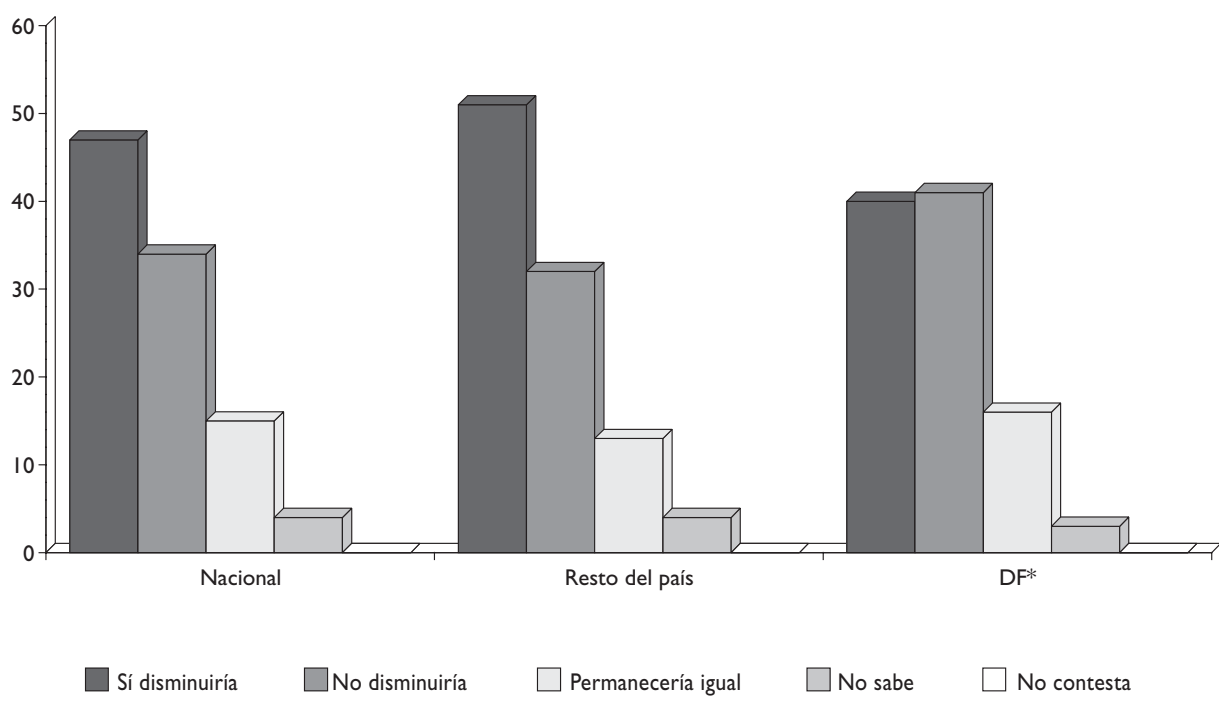

* La pregunta cambió papra el DF por la Ley de Protección a los No Fumadores que recientemente aprobó la Asamblea Legislativa del Distrito Federal Fuente: Parametría y Consejo Mexicano Contra el Tabaquismo

Figura 7. Implicaciones de tener espacios libres de humo de tabaco. México, 2008 


\section{Nota metodológica}

Encuesta Nacional en Vivienda realizada por el Consejo Mexicano contra el Tabaquismo y Parametría

Representatividad: Nacional y Distrito Federal. Número de entrevistas: 400 en el DF y 800 en el resto del país. Nivel de confianza estadística: 95\%. Margen de error
+/-4.9\% en el DF y +/-3.5\% en el resto del país. Diseño, muestreo, operativo de campo y análisis: Parametría SA de CV. Método de muestreo: Aleatorio sistemático con probabilidad proporcional al tamaño. Unidad de muestreo: Las secciones electorales reportadas por el Instituto Federal Electoral. Fecha de levantamiento: del 9 al 16 de febrero de 2008. 